\title{
CLIMA 2019-Modelling study on pipe-encapsulated PCM wall system for building insulation and active heat removal
}

\author{
Tian $\mathrm{Yan}^{1}$, Xinhua $\mathrm{Xu}^{1, *}$, and Jiajia $\mathrm{Gao}^{1}$ \\ ${ }^{1}$ Department of Building Environment \& Energy Engineering, Huazhong University of Science \& Technology, 430074 Wuhan, China
}

\begin{abstract}
Phase change material (PCM) can be used in building envelope for heat insulation and energysaving. However, the energy-saving effect of the PCM wall system is limited in summer since the PCM storing heat in the daytime will become a secondary heat source and release heat into the room again at night. This paper proposed a novel pipe-encapsulated PCM wall system. It integrates phase change technology and nocturnal radiation cooling technology together to realize building insulation and active heat removal. A simulation platform is established for the thermal performance simulation of this wall system. It mainly includes the simplified pipe-encapsulated PCM wall model and nocturnal radiation model. The simplified wall model includes the 5R2C wall model, 4R2C PCM model and 2R1C pipe model. The model parameters are identified and the model is also validated with good accuracy. Based on this platform, the thermal performance of a light weight room with pipe-encapsulated PCM wall system in Wuhan is simulated. About $50 \%-60 \%$ of heat from the outdoor environment can be conserved by the pipeencapsulated PCM wall, and $50 \%$ of that can be removed by the radiant cooler at night. Results show the pipe-encapsulated PCM wall system has good thermal performance for light weight building.
\end{abstract}

Keywords. Pipe-encapsulated PCM wall system, Nocturnal radiation cooling, Active heat removal, Simplified $\mathrm{RC}$ model, Thermal performance

\section{Introduction}

With the rapid development of urbanization, the energy consumption of buildings increases day by day. The high energy-efficiency building structures/systems have been widely concerned by people. In recent years, the phase change materials (PCMs) are widely used in buildings for improving thermal and energy performance of buildings. PCMs can absorb or release a lot of latent heat high at a certain temperature or temperature interval by changing its phase state, which shows high energy density. For the building envelops, the PCMs can be incorporated into walls, ceilings and floors to realize building insulation, reduce the peak load and energy consumption of air-conditioning or heating system of buildings [1-2].

The applications and thermal performances of PCMs in buildings have been widely investigated. Elarga et al. [3] investigated the thermal performances of PCM integrated in a roof space to be used as a residential attic. Three different PCM utilization modes were applied to a roof continuously monitored under summer climatic conditions. Experimental results showed a reduction of the ongoing heat peak load between $13 \%$ and $59 \%$ with the different the PCM typology. Kim et al. [4] examined three identical huts to discuss the thermal performance effect of PCM under heating conditions. Compared with the reference hut without SSPCM sheet (i.e., hut A), the total energy consumption for heating decreased by $9.2 \%$ and $18.4 \%$ in hut B (four layers of SSPCM sheets were applied to the floor) and hut C (one layer of SSPCM was applied to the floor, walls and ceiling) respectively.

The conventional PCM wall systems can effectively decrease the energy consumption of heating systems in winter. However, in summer, the energy-saving potential of PCM wall is limited since the PCM stored heat in the daytime will become a secondary heat source and release the stored heat into the room again at night. The heat accumulated at night will significantly increase the air conditioning energy consumption of the room in the next day. Diaconu et al. [5] investigated the annual energy performances of a sandwich PCM exterior wall in the Mediterranean climate (Algeria). Results showed that the energy consumption of the heating system in winter was reduced by $12.8 \%$. But in summer, the cooling energy consumption of air-conditioning system was only reduced by $1 \%$.

To improve the energy efficiency of buildings with PCM system, a novel pipe-encapsulated PCM wall system with nocturnal sky radiant cooler is developed to realize building insulation and active heat removal in this paper. The nocturnal radiant cooler is a very efficient cooling device by long-wave radiation. It can provide cold water for direct or auxiliary room radiant cooling [6-7]. In the daytime of summer, the pipe-encapsulated PCM of this wall system can absorb the heat from the outer wall and stored it in the form of latent heat. At

\footnotetext{
* Corresponding author: bexhxu@hust.edu.cn
} 
night, the heat of the PCM can be taken away by the working fluid through the nocturnal sky radiant cooler.

Traditional PCM thermal models are generally numerical models. Chen et al. [8] developed non-linear numerical model for a PCM wallboard based on the effective heat capacity method. The parameters effects including the phase change temperature, specific heat and density on the thermal characteristics of the PCM were discussed. Lamberg et al. [9] simulated the heat transfer characteristics of a kind of paraffin by two numerical models using the effective enthalpy method and the effective heat capacity method respectively. The feasibility of the two methods was further discussed by the experiment. These numerical models are accurate and widely used. But it is too complicated for pipeencapsulated PCM to be coupled with wall model, pipe heat transfer model and the nocturnal sky radiation model. The computational efficiency is also low. It is not applicable for integrated simulation of the thermal performances of pipe-encapsulated PCM wall system.

This paper proposes a novel pipe-encapsulated PCM wall system for building insulation and active heat removal. The simplified thermal RC model of pipeencapsulated PCM wall coupled by the simplified common hollow wall model, simplified PCM model and pipe heat transfer model is developed. The model parameters are identified and the model are validated by CFD model. Besides, the simulation platform integrated with the simplified pipe-encapsulated PCM wall model and nocturnal sky radiation is established. A simple simulation case about the thermal performance of a light weight room with the pipe-encapsulated PCM wall system are presented.

\section{Description of pipe-encapsulated PCM wall system}

The pipe-encapsulated PCM wall for building insulation and active heat removal is illustrated in Fig.1. It is composed of the pipe-encapsulated PCM wall, nocturnal sky radiant cooler and working fluid circulation system. The pipe-encapsulated PCM is composed of inner pipe, outer pipe, PCM and working fluid for heat removal. It can be embedded into the common wall as the PCM structure of thermal storage and insulation for building envelopes. The PCM is encapsulated between the inner and outer pipe to absorb heat from the brick wall, and the working fluid is filled with inner pipe for heat removal. The circulating pipeline of the working fluid circulation system connects the nocturnal sky radiant cooler with the inter pipe. By this circulation system, the circulating working fluid can absorb the heat from PCM and discharge it into space through the nocturnal sky radiant cooler by long-wave radiation.

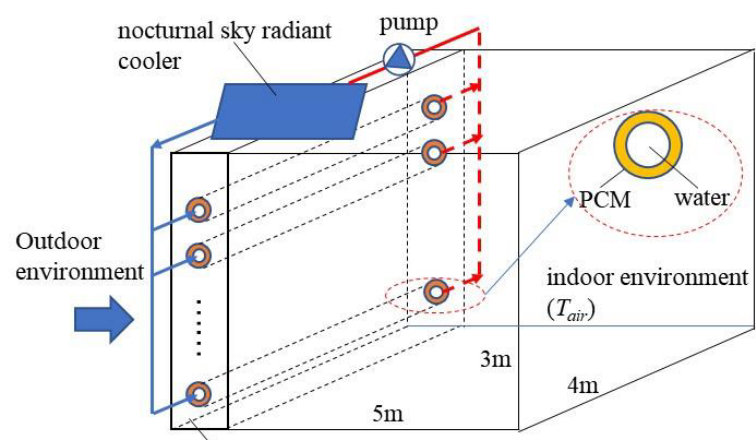

Pipe-encapsulated PCM wall

Fig.1. The schematic of the pipe-encapsulated PCM wall for building insulation and active heat removal

In the daytime of summer, the temperature of the outdoor environment is high and a lot of heat enters the external wall of building. The pipe-encapsulated PCM wall system uses the pipe-encapsulated PCM embedded inside the brick wall to absorb the heat of the external wall and store it in the form of latent heat. It can effectively reduce the cooling load of building formed by the heat transfer of the external wall. In the night-time, the circulatory working fluid absorbs the heat of the PCM and discharges it into space through the nocturnal sky radiant cooler. The stored heat in the PCM are removed and the PCM is also regenerate for heat storage and insulation in the second day. The working fluid can be water or other medium and its circulating power can be supplied by pump. By this wall system, the accumulation of heat entering the room in the daytime are transfer to space in the night-time, which can reduce significantly the heat gains of building from the outdoor environment.

\section{Simplified thermal model}

The simplified thermal of the pipe-encapsulated PCM wall system is composed of the common wall simplified model, simplified PCM model, simplified pipe heat transfer model and nocturnal sky radiation model. These models can be easily integrated together for the predictions of thermal performance of the pipeencapsulated PCM wall system with the dynamic boundary conditions.

\subsection{Simplified thermal model for pipe- encapsulated PCM wall}

The simplified RC-network thermal models are widely used in building envelops [10-11]. The pipeencapsulated PCM wall structure includes common hollow wall, pipe-encapsulated PCM and embedded pipe. The simplified thermal model of this wall structure for the analysis object can be coupled by the simplified wall model (5R2C model), simplified PCM model (4R2C model), and pipe thermal model (2R1C model). The schematic of the pipe-encapsulated PCM wall and its simplified thermal model are illustrated in Fig.2. 


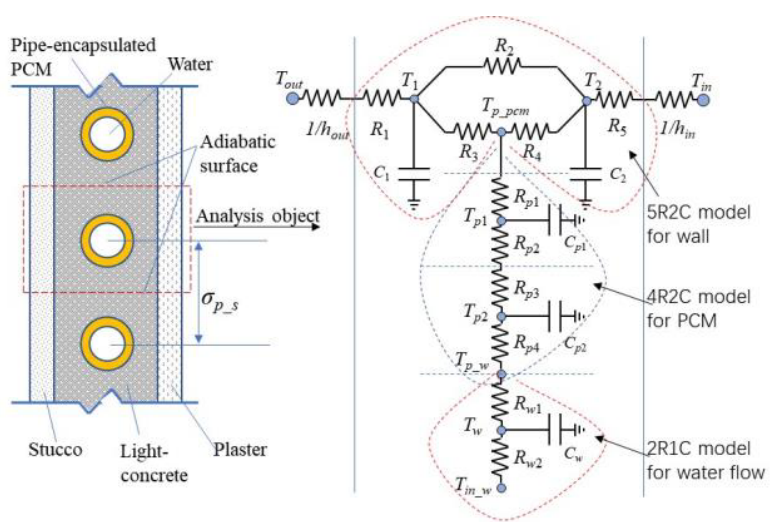

(a) Wall Structure

(b) Simplified thermal model

Fig.2. The schematic of the pipe-encapsulated PCM wall structure $(a)$ and the simplified thermal model $(b)$

\subsubsection{R2C model for Common hollow wall}

As the Fig.2(b), a 5R2C (five thermal resistance and two thermal capacitance) thermal model for an analysis object is proposed referring to Ref. [12]. In this model, $R_{2}$ is considered since there is direct heat conduct in the solid wall mass. $T_{p p c m}$ is the node temperature of the external surface of the pipe-encapsulated PCM, and there are two thermal resistances $\left(R_{3}, R_{4}\right)$ at both sides of this node. Besides, two thermal capacitance nodes are considered in the both sides of pipe to represent the effect of the thermal capacitance. Usually, two-order model including five lumped resistances and two lumped capacitances may well represent the dynamic characteristics of common hollow wall with the outdoor and indoor temperature boundary (i.e., $T_{\text {out }}, T_{\text {in }}$ ).

The RC parameters (i.e., $R_{1}, R_{2}, R_{3}, R_{4}, R_{5}, C_{1}, C_{2}$ ) of the $5 \mathrm{R} 2 \mathrm{C}$ model is constant for common wall structure, and they are identified by GA (Genetic Algorithm) in the next session. Besides, the convection heat transfer resistance of internal surface and external surface are simply calculated by the surface convection heat transfer coefficients (i.e., $h_{\text {in }}$ and $h_{\text {out }}$ ).

\subsection{2. $4 R 2 C$ model for pipe-encapsulated PCM}

For pipe-encapsulated PCM, the resistances and heat mass are variable due to the phase change latent heat. Thus, a two-order RC model with four variable resistances and two variable capacitances for the pipeencapsulated PCM are developed, as shown in Fig.2(b). In this model, the cylindrical PCM is divided into two sub-cylinders with two internal temperature nodes (i.e., $T_{p 1}, T_{p 2}$ ), and each sub-cylinder is represented as one effective lumped capacitance and two effective lumped resistances. These effective thermal capacitances and thermal resistances are variable with the node temperature (i.e., $R_{p 1}, R_{p 2}$ and $C_{p 1}$ are variable with; $R_{p 3}$, $R_{p 4}$ and $C_{p 2}$ are variable with the node temperature $T_{p 2}$ ). The dynamic thermal characteristics of the pipeencapsulated PCM may be well predicted by this simplified 4R2C model.

The variable $\mathrm{RC}$ parameters $\left(R_{p 1}, R_{p 2}, R_{p 3}, R_{p 4}, C_{p 1}\right.$, $C_{p 2}$ ) of this PCM model are calculated by the distribution ratios and the total resistances and capacitances of the pipe-encapsulated PCM, and the distribution ratios are also defined and identified in the next session.

\subsection{3. $2 R 1 C$ model for heat transfer of water in the pipe}

A $2 \mathrm{R} 1 \mathrm{C}$ model is developed to represent the heat transfer along the direction of the water flow in the pipe referring Ref. [13], as shown in Fig.2(b). This model represents the relation between the inlet water temperature $\left(T_{w}\right)$ and the pipe surface temperature $\left(T_{P_{-} w}\right)$. The equivalent RC parameters $\left(R_{w 1}, R_{w 2}\right.$ and $\left.C_{w}\right)$ are defined based on an energy balance equation about the water flow which is established by using the $\varepsilon$-NTU method [14]. Those parameters can be simply derived from the heat balance formulas in the steady heat transfer of the water flow, as expressed in Eqs.(1)-(3).

$$
\begin{gathered}
C_{w} \frac{d T_{w}}{d t}=m c_{p_{-} w}\left(T_{\text {in_w }}-T_{\text {out } t_{-}}\right)+h_{w} A_{w}\left(T_{p_{-} w}-T_{w}\right) \\
=\frac{T_{p 2}-T_{w}}{R_{p 4}+R_{w 1}}-\frac{T_{w}-T_{\text {in } w} w}{R_{w 2}} \\
R_{w 1}=\frac{1}{h_{w} A_{w}}, R_{w 2}=\frac{1}{\varepsilon m c_{p_{-} w}}-\frac{1}{h_{w} A_{w}}, C_{w}=\frac{\pi d^{2} l}{4} \rho_{w} m \\
\varepsilon=\frac{T_{\text {in_w }}-T_{\text {out_w }}}{T_{\text {in_w }}-T_{p_{-} w}}=1-e^{-N T U}, N T U=\frac{h_{w} A_{w}}{m c_{p_{-} w}}
\end{gathered}
$$

Where, $h_{w}$ is the convective heat transfer coefficient of the internal surface of pipe, $\mathrm{W} / \mathrm{m}^{2} \mathrm{~K} ; A_{w}$ is the internal surface area of pipe, $\mathrm{m}^{2} ; m$ is the water flow rate, $\mathrm{kg} / \mathrm{s} ; l$ is the length of pipe, $\mathrm{m} ; T_{\text {in } w}, T_{\text {out } w}$ are respectively the inlet water temperature and outlet water temperature, ${ }^{\circ} \mathrm{C}$; $\rho_{w}$ is the density of water, $\mathrm{kg} / \mathrm{m}^{3} ; c_{p_{-} w}$ is the specific heat of water, $\mathrm{J} / \mathrm{kgK}$.

\subsubsection{Heat balance equations for the simplified model of the pipe-encapsulated PCM wall}

The simplified model of the pipe-encapsulated PCM wall can be easily established by integrating with the common hollow wall model, PCM model and pipe heat transfer model. The heat balance for the simplified model can be expressed by the differential equations as the Eqs.(4)-(9).

$$
\begin{array}{r}
C_{1} \frac{d T_{1}}{d t}=\frac{T_{\text {out }}-T_{1}}{1 / h_{\text {out }}+R_{1}}-\frac{T_{1}-T_{2}}{R_{2}}-\frac{T_{1}-T_{p_{-} p c m}}{R_{3}} \\
C_{2} \frac{d T_{2}}{d t}=\frac{T_{1}-T_{2}}{R_{2}}+\frac{T_{p_{-} p c m}-T_{2}}{R_{4}}-\frac{T_{2}-T_{\text {in }}}{R_{5}+1 / h_{\text {in }}} \\
0=\delta_{p_{-} s} \frac{T_{1}-T_{p_{-} p c m}}{R_{3}}+\frac{T_{2}-T_{p_{-} p c m}}{R_{4}}-\frac{T_{p_{-} p c m}-T_{p 1}}{R_{p 1}} \\
C_{p 1} \frac{d T_{p 1}}{d t}=\frac{T_{p_{-} p c m}-T_{p 1}}{R_{p 1}}-\frac{T_{p 1}-T_{p 2}}{R_{p 2}+R_{p 3}}
\end{array}
$$




$$
\begin{gathered}
C_{p 2} \frac{d T_{p 2}}{d t}=\frac{T_{p 1}-T_{p 2}}{R_{p 2}+R_{p 3}}-\frac{T_{p 2}-T_{w}}{R_{p 4}+R_{w 1}} \\
C_{w} \frac{d T_{w}}{d t}=\frac{T_{p 2}-T_{w}}{R_{p 4}+R_{w 1}}-\frac{T_{w}-T_{i n_{-} w}}{R_{w 2}}
\end{gathered}
$$

Where, $T$ is the temperature, ${ }^{\circ} \mathrm{C} ; R, C$ are respectively thermal resistance and capacitance; $\sigma_{p_{-} s}$ is the pipe spacing, $\mathrm{m}$.

The heat flow of the external surface $\left(Q_{e x}\right)$ and internal surface $\left(Q_{i n}\right)$ can be calculated by Eq.(10). The heat flow removing by the water $\left(Q_{\text {water }}\right)$ in the pipe can be calculated by Eq.(11).

$$
\begin{gathered}
Q_{\text {ex }}=A \frac{T_{\text {out }}-T_{1}}{1 / h_{\text {out }}+R_{1}}, Q_{\text {in }}=A \frac{T_{2}-T_{\text {in }}}{1 / h_{\text {in }}+R_{5}} \\
Q_{\text {water }}=l \frac{T_{p 2}-T_{w}}{R_{p 4}+R_{w 1}}
\end{gathered}
$$

\subsection{Nocturnal sky radiation model}

In the night-time, the heat transfer between the nocturnal sky radiant cooler and surrounding environment $\left(q_{\text {cooler }}\right)$ mainly includes night long-wave radiation heat transfer $\left(q_{\mathrm{rad}}\right)$ and convection heat transfer $\left(q_{\text {conv }}\right)$, as expressed in Eqs.(12)-(14) [15].

$$
\begin{aligned}
q_{\text {cooler }} & =q_{\text {rad }}+q_{\text {conv }} \\
q_{\text {rad }} & =A_{\text {rad }} \varepsilon_{\text {rad }} \sigma\left(T_{r a d}{ }^{4}-T_{s k y}{ }^{4}\right) \\
q_{\text {conv }} & =h_{\text {conv }} A_{\text {rad }}\left(T_{r a d}-T_{a m b}\right)
\end{aligned}
$$

Where, $\varepsilon_{\text {rad }}$ is the surface emissivity of the nocturnal sky radiant cooler; $\sigma$ is the Stefan-Boltzmann constant, $5.67 \times 10-8 \mathrm{~W} / \mathrm{m}^{2} \mathrm{~K} ; A_{\text {rad }}$ is the heat transfer area of the nocturnal sky radiant cooler, $\mathrm{m}^{2} ; T_{\text {rad }}$ is the temperature of the radiant cooler, which can be simply defined as the average value of the inlet temperature and outlet temperature of the medium, $\left(T_{\text {inlet }}+T_{\text {outlet }}\right) / 2, \mathrm{~K} . T_{\text {sky }}$ is the equivalent sky temperature for long-wave radiation, $\mathrm{K}$. $h_{\text {conv }}$ is the convective heat transfer coefficient for radiant cooler, W/ $\mathrm{m}^{2} \mathrm{k}$. It can be calculated by Eq.(15)[16].

$$
h \operatorname{conv}= \begin{cases}3.5 & V<1.35 \\ 2.8+0.76 V & 1.35<V<5\end{cases}
$$

Where $V$ is the wind speed of the ambient air, $\mathrm{m} / \mathrm{s}$.

The equivalent sky temperature for sky long-wave radiation $\left(T_{s k y}\right)$ is a virtual temperature defined as the temperature of a black body radiator emitting the same amount of radiative power as the sky [17]. It can be expressed by the empirical formulas as follows $[16,18]$.

$$
\begin{gathered}
T_{\text {sky }}=\sqrt[4]{c_{a} \varepsilon_{\text {sky }}} T_{\text {amb }} \\
\varepsilon_{\text {sky }}=0.711+0.0056\left(T_{d p}-273\right)+0.000073\left(T_{d p}-273\right)^{2}(17) \\
c_{a}=1+0.0224 n_{\text {cloud }}-0.0035 n_{\text {cloud }}{ }^{2}+0.00028 n_{\text {cloud }}{ }^{3}
\end{gathered}
$$

Where, $c_{a}$ is the cloudiness coefficient, $\varepsilon_{\text {rad }}$ is the emissivity of clear sky, $n_{\text {cloud }}$ is the total opaque cloud amount, which $n_{\text {cloud }}=0$ represents the clear sky, $n_{\text {cloud }}=1$ represents the overcast sky; $T_{d p}$ is the dew point temperature of ambient air, $\mathrm{K}$.

The system simplified model can be easily integrated with the simplified model of pipe-encapsulated PCM wall and the nocturnal sky radiation model. The parameter identification and validation of the pipeencapsulated PCM wall model are further proposed in the next session, and a case study for the thermal performance of the whole wall system is also presented by using the system simplified model.

\section{Parameter identification and model validation}

To identify the parameters of models (5R2C wall model and 4R2C PCM model) and validate the simplified model of pipe-capsulated PCM wall, the heat transfer characteristics of a light weight wall are simulated by the simplified model and CFD model. The structure of the pipe-encapsulated PCM wall is shown in Fig.2, and its thermal properties are listed in Table 1. The composite PCM is composed of $80 \mathrm{wt} \%$ RT28 and $20 \mathrm{wt} \% \mathrm{EG}$ (expanded graphite) to improve its thermal conductivity. The phase change temperature is $26.9-28.9^{\circ} \mathrm{C}$ and the phase change latent heat is $160.2 \mathrm{~kJ} / \mathrm{kg}$. The inner and outer diameter of PCM are respectively $15 \mathrm{~mm}$ and $32 \mathrm{~mm}$. The pipe spacing is $200 \mathrm{~mm}$. To simplify the parameter identification and model validation, the water in the inner pipe are assumed as an internal thermal capacitance without flow. The CFD model for the light wall with pipe-encapsulated PCM is established on ANSYS software.

Table 1. Thermal properties of the light weight pipeencapsulated PCM wall.

\begin{tabular}{|c|c|c|c|c|}
\hline Item & $\begin{array}{c}\text { Thickne } \\
\text { ss (mm) }\end{array}$ & $\begin{array}{c}\text { Thermal } \\
\text { conductivity } \\
(\mathrm{W} / \mathrm{mk})\end{array}$ & $\begin{array}{c}\text { Specific } \\
\text { heat } \\
(\mathrm{J} / \mathrm{kgK})\end{array}$ & $\begin{array}{c}\text { Density } \\
\left(\mathrm{kg} / \mathrm{m}^{3}\right)\end{array}$ \\
\hline Stucco & 20 & 0.692 & 840 & 1858 \\
\hline $\begin{array}{c}\text { Light- } \\
\text { concrete }\end{array}$ & 100 & 0.571 & 840 & 609 \\
\hline plaster & 20 & 0.727 & 840 & 1602 \\
\hline PCM & 8.5 & $9.5(s) / 9.7(l)$ & 2000 & 750 \\
\hline
\end{tabular}

\subsection{Parameters identification}

\subsubsection{Parameters identification of 5R2C model}

The parameter identification method of the 5R2C model for the common wall is briefly given here. The details can be found in the Ref. [15]. The optimization process is actually searching the optimal values of the $\mathrm{RC}$ 
parameters, which allow the frequency of the 5R2C model best fit the reference results. The thermal response using the frequency-domain finite element (FDFE) is solved as the reference results in this paper. The objective function of such optimization is expressed in Eq. (19).

$$
\begin{aligned}
& J_{5 R 2 C}\left(R_{1}, R_{2}, R_{3}, R_{4}, R_{5}, C_{1}, C_{2}\right)=\sum_{n=1}^{N} \sum_{k=1,2,3} \sum_{m=I, E, P} \\
& \left(W_{m, k}^{A M}\left|\begin{array}{l}
A M\left(q_{m, k}\left(j w_{n}\right)\right)- \\
A M\left(q_{m, k}^{\prime}\left(j w_{n}\right)\right)
\end{array}\right|+W_{m, k}^{P A}\left|\begin{array}{l}
P A\left(q_{m, k}\left(j w_{n}\right)\right)- \\
P A\left(q_{m, k}^{\prime}\left(j w_{n}\right)\right)
\end{array}\right|\right)
\end{aligned}
$$

Where, $J$ is the objective function; $q_{m, k}$ and $q_{m, k}^{\prime}$ are respectively the frequency thermal response prediction of the 5R2C model and FDFE model. $A M(\cdot)$ and $P A(\cdot)$ are the amplitude and the phase lag of complex variables respectively. $m$ represents the surface (i.e., $m=I$ represents the internal surface, $m=O$ represents the external surface and $m=P$ represents the inner pipe surface of the wall). $W$ is the weight factor. The subscript $k$ is the $k$-th characteristic disturbance (i.e., internal, external and pipe surface characteristic disturbance). $w_{n}$ is the $n$-th frequency point, $\mathrm{rad} / \mathrm{s} ; N$ is the number of the discrete frequency points among the chosen frequency range for parameter identification, i.e., from $10-8 \mathrm{rad} / \mathrm{s}$ $(1.74 \times 105 \mathrm{~h})$ to $10-3 \mathrm{rad} / \mathrm{s}(1.74 \mathrm{~h})[15]$.

The constraint conditions of such optimization are expressed in Eq.(20). Where $R_{\text {totwall }}, C_{\text {totwall }}$ are the total thermal resistance and capacitance of the common wall without the pipe-encapsulated PCM respectively.

$$
\begin{aligned}
& 0<R_{1}, R_{5}<R_{\text {totwall }} \\
& 0<R_{2}, R_{3}, R_{4}<4 R_{\text {totwall }} \\
& 0<C_{1}, \quad C_{1}<C_{\text {totwall }} \\
& 0<R_{1}+\frac{R_{2}\left(R_{3}+R_{4}\right)}{R_{2}+R_{3}+R_{4}}+R_{5}<R_{\text {totwall }} \\
& 0<C_{1}+C_{2}<C_{\text {totwall }}
\end{aligned}
$$

\subsubsection{Parameters identification of $4 R 2 C$ model}

When the parameters of 5R2C model are obtained, the PCM model parameters can be further identified by the CFD model. The optimization process is actually searching the optimal distribution ratios of the RC parameters, which allow the thermal response of the whole wall structure best fit the reference results. The CFD model is the reference model. The parameter identification method of 4R2C model is briefly described referring to Ref. [19]. The objective function of such optimization is expressed in Eq. (21).

$$
J_{4 R 2 C}\left(\beta_{1}, \beta_{2}, \beta_{3}\right)=\sqrt{\frac{\sum_{k=1}^{N}\left(Q_{i n}-Q_{i n}^{\prime}\right)^{2}}{N-1}}
$$

Where, $J$ is the objective function, $Q_{\text {in }}$ and $Q^{\prime}{ }_{\text {in }}$ are respectively the heat flux prediction of internal surface of the simplified model and CFD model. $\beta_{i}$ is optimization variables (i.e., $\beta_{1}$ is the ratio of the total capacitance and resistance of first sub-cylinder of the total capacitance $\left(R_{\mathrm{PCM}}\right)$ and resistance $\left(C_{\mathrm{PCM}}\right)$ of the whole cylindrical PCM at a coincident node temperature. $\beta_{2}$ is the resistance ratio of the first sub-cylinder. $\beta_{3}$ is the resistance ratio of the second sub-cylinder). The $\mathrm{RC}$ parameters can be calculated by these variables, as expressed in Eqs.(22)-(24). The constraint conditions of the optimization variables are 0 to 1 (i.e., $0<\beta_{1}, \beta_{2}, \beta_{3}<1$ ).

$$
\begin{gathered}
R_{p 1}=\beta_{1} \beta_{2} R_{p c m}\left(T_{p 1}\right), R_{p 2}=\beta_{1}\left(1-\beta_{2}\right) R_{p c m}\left(T_{p 1}\right)(22) \\
R_{p 3}=\left(1-\beta_{1}\right) \beta_{3} R_{p c m}\left(T_{p 2}\right), R_{p 4}=\left(1-\beta_{1}\right)\left(1-\beta_{3}\right) R_{p c m}\left(T_{p 2}\right) \\
C_{p 1}=\beta_{1} C_{p c m}\left(T_{p 1}\right), C_{p 2}=\left(1-\beta_{1}\right) C_{p c m}\left(T_{p 2}\right)
\end{gathered}
$$

The total resistance $\left(R_{\mathrm{pcm}}\right)$ and capacitance $\left(C_{\mathrm{pcm}}\right)$ per unit length of the PCM encapsulated between the inner pipe and the outer pipe are simply expressed in Eqs. (25)-(26). They are variable with the node temperature.

$$
\begin{gathered}
R_{P C M}(T)=\frac{1}{2 \pi \lambda_{p}(T)} \ln \frac{d_{\text {out }}}{d_{\text {out }}-d_{\text {in }}} \\
C_{P C M}(T)=\frac{1}{4} \pi\left(d_{\text {out }}{ }^{2}-d_{\text {in }}{ }^{2}\right) \rho_{p_{p} c_{p_{-} p}}(T)
\end{gathered}
$$

The equivalent thermal conductivity $\left(\lambda_{p}\right)$ is expressed in Eq.(27). The equivalent specific heat $\left(c_{p p}\right)$ of PCM can be simply the linear function of the temperature, as illustrated in Fig.3. Where $\lambda_{s}, \lambda_{l}$ are respectively the thermal conductivity of solid phase PCM and liquid phase PCM, W/mK; $c_{p_{-} s}, c_{p_{-} l}$ are respectively the specific heat of solid phase PCM and liquid phase PCM, J/kgK; $L$ is the phase change latent heat of PCM, $\mathrm{J} / \mathrm{kg} ; T_{s}, T_{l}$ are respectively solidification temperature and melting temperature of PCM, ${ }^{\circ} \mathrm{C}$.

$$
\lambda_{p}(T)=\left\{\begin{array}{lc}
\lambda_{s} & T<T_{s} \\
\left(T-T_{s}\right)\left(\lambda_{l}-\lambda_{s}\right) /\left(T_{l}-T_{s}\right) & T_{s} \leq T \leq T_{l}(27) \\
\lambda_{l} & T>T_{l}
\end{array}\right.
$$

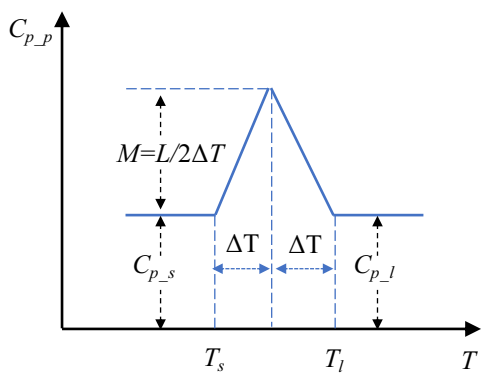

Fig. 3 The equivalent specific heat of PCM

\subsubsection{Model Parameters Results}

The RC parameters of the 5R2C simplified wall model are identified by FDFD wall model, and the independent parameters of the 4R2C simplified PCM model are identified by using the CFD model of the 
pipe-encapsulated PCM wall. The identified parameters are listed in Table 2.

Table 2. The RC parameters of simplified model

\begin{tabular}{|c|c|c|c|c|c|c|}
\hline model & & $R_{1}$ & $R_{2}$ & $R_{3}$ & $R_{4}$ & $R_{5}$ \\
\hline \multirow{2}{*}{$5 \mathrm{R} 2 \mathrm{C}$} & & 0.0625 & 0.2019 & 0.1155 & 0.2082 & 0.0293 \\
\hline & $C$ & \multicolumn{5}{|c|}{$\mathrm{C}_{1}=43713.6007, \mathrm{C}_{2}=43713.6007$} \\
\hline \multirow{2}{*}{$4 \mathrm{R} 2 \mathrm{C}$} & $R$ & \multicolumn{5}{|c|}{$\begin{array}{l}R_{p 1}=0.170 R_{P C M}\left(T_{p 1}\right), R_{p 2}=0.040 R_{P C M}\left(T_{p 1}\right) \\
R_{p 3}=0.474 R_{P C M}\left(T_{p 1}\right), R_{p 4}=0.316 R_{P C M}\left(T_{p 1}\right)\end{array}$} \\
\hline & $C$ & \multicolumn{5}{|c|}{$C_{p 1}=0.21 C_{P C M}\left(T_{p 1}\right), C_{p 2}=0.79 C_{P C M}\left(T_{p 2}\right)$} \\
\hline
\end{tabular}

\subsection{Model validation}

Using the identified parameters, the internal surface temperature, heat flux and water temperature are predicted by the simplified model, and the predictions of simplified model are compared with the predictions of CFD model. In this validation case, the convective heat transfer coefficients of external surface and internal surface are respectively $22.7 \mathrm{~W} / \mathrm{m}^{2} \mathrm{k}$ and $8.3 \mathrm{~W} / \mathrm{m}^{2} \mathrm{k}$ from the ASHRAE handbook [20]. The air film temperature of internal surface is $26^{\circ} \mathrm{C}$, and the air film temperature of external surface is simply expressed in a sine function with the period of 24 hours, as shown in Eq.(28) .

$$
T_{\text {out }}=31.3-8.02 \times \sin (2 \pi t / 86400+3 \pi / 5)
$$

Fig.4 Shows the comparison between the internal surface temperature of the pipe-encapsulated PCM wall predicted by simplified model and CFD model. The profile of internal surface temperature predicted by simplified model may match well with the temperature profile predicted by the CFD model. The average temperature error is about $0.14^{\circ} \mathrm{C}$, which shows that the simplified model can accurately predict the internal surface temperature with the dynamic boundary.

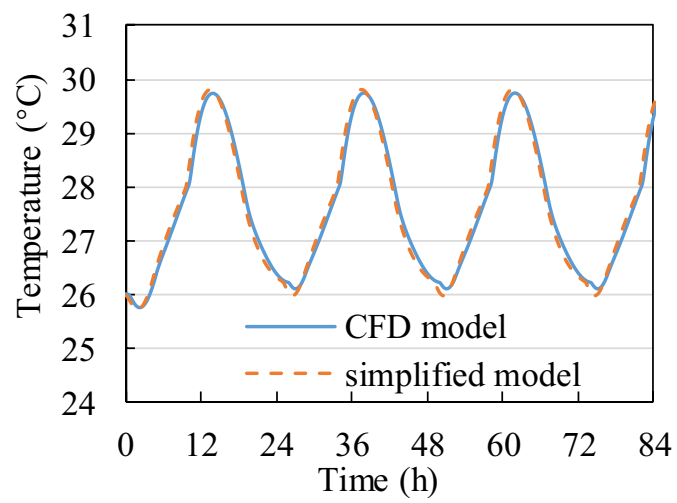

Fig.4. Internal surface temperature of the pipe-encapsulated PCM wall
Fig.5 Shows the comparison between the internal surface heat flux of the pipe-encapsulated PCM wall predicted by simplified model and CFD model. The heat flux profile of internal surface predicted by simplified model almost overlaps with the heat flux profile predicted by the CFD model. The average heat flux error is about $1.5 \mathrm{~W}$, and the accumulated heat flow error for 24 hours (one period) is about $1 \%$. It shows that the thermal response predicted by the simplified model is very reliable.

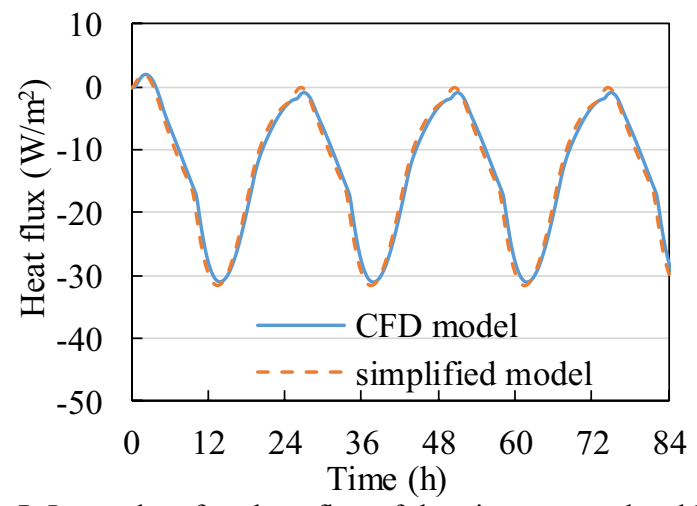

Fig.5. Internal surface heat flux of the pipe-encapsulated PCM wall

The temperature profiles of water in the inner pipe predicted by the simplified model and CFD model are shown in Fig.6. Due to the phase change latent heat, there are two inflection point when the temperature is in the range of phase change temperature. The water temperature profile predicted by the simplified model may also match well with the profile predicted by the CFD model. the average error is only $0.16^{\circ} \mathrm{C}$.

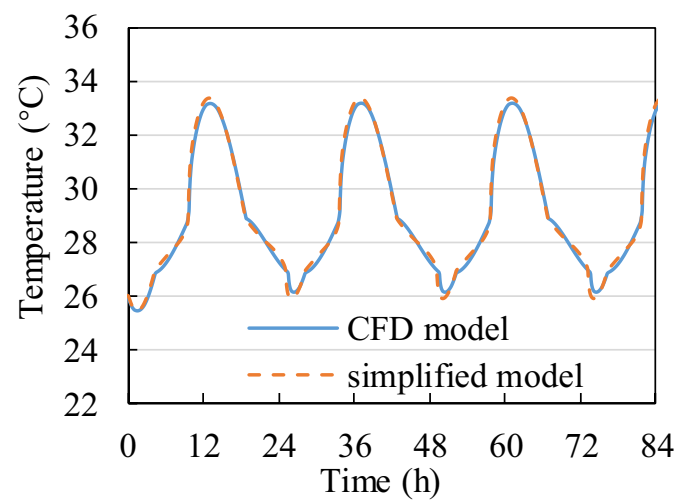

Fig. 6. Temperature of water in the inner pipe

The predictions including the temperature and heat flux of simplified model match well with the results predicted by the CFD model. It shows that the accuracy of the simplified model is acceptable and reliable. Besides, the computation time of the CFD model is about 4 hours, but it only takes 5 seconds for the simplified model in the same computer (i7 processor, 8 gigabytes of memory) to predict the thermal response of the pipe-encapsulated PCM wall. The computational efficiency of the simplified model is significantly higher than the CFD model. 


\section{Case study}

In this paper, a very simple simulation case about the thermal performance of a light weight room with pipeencapsulated PCM wall system are proposed. The test room for the case is illustrated as the Fig.1. To simplify this study, the room is only affected the heat disturbance of the pipe-encapsulated PCM wall facing south direction. The other three walls, ceiling and floor are assumed as the adiabatic surfaces. The size of the pipeencapsulated PCM wall is $3 \mathrm{~m}$ (height) $\times 4 \mathrm{~m}$ (width), and the pipe interval is $200 \mathrm{~mm}$. The thermal properties of the wall system are same as the model validation case. The heat transfer area of the nocturnal sky cooler is $10 \mathrm{~m}^{2}$. The model parameters are shown in Table 1 of Session 4. The outdoor environment boundary is given in the form of air operating temperature on 11-15 July (i.e., 120 hours) for the south wall of building in Wuhan, as presented in Fig.7. Wuhan city is located in the centre of China and it is very hot in summer. The indoor environment is at air-conditioning conditions, the indoor air temperature is controlled by air-conditioner at $26{ }^{\circ} \mathrm{C}$ in office hour (8:00-18:00) and the nocturnal sky cooler (pump) is operating at night-time (18:00-8:00).

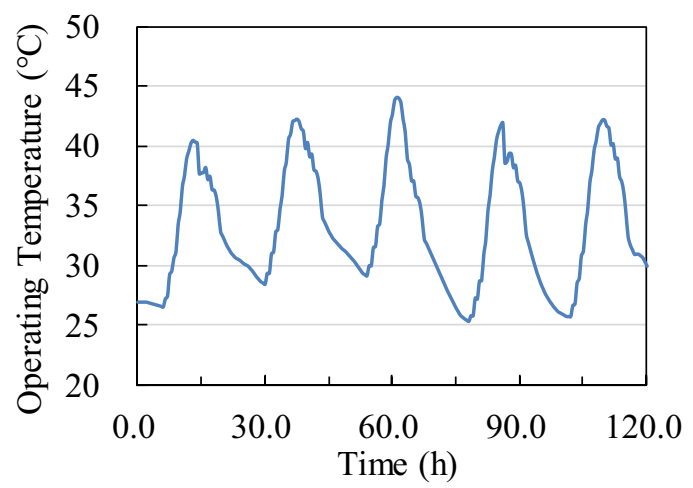

Fig.7. Outdoor air operating temperature of the south wall

The simulation platform of pipe-encapsulated PCM wall system integrated with the simplified pipeencapsulated PCM wall model and nocturnal sky radiation model is established in TRNSYS 16, as shown in Fig.8. Based on this platform, the temperature and heat flow of wall surface of the test toom are predicted and discussed, and the heat removal of the water by the sky radiant cooler is also presented.

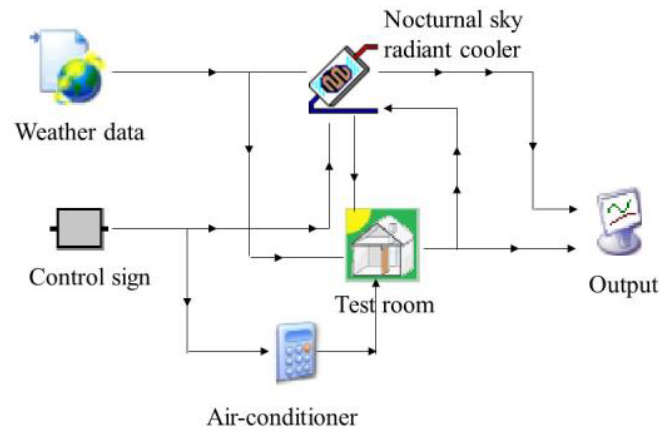

Fig.8. Simulation platform of the pipe-encapsulated PCM wall system
Fig.9 presents the predictions of heat flow of the external surface and internal surface of the pipeencapsulated PCM wall. And the heat removal by water through the nocturnal sky radiant cooler is also presented. In the daytime (i.e., office hour), the heat flow of external surface can reach up to $0.9 \mathrm{~kW}$, and it is significantly larger than the heat flow of internal surface (less than $0.5 \mathrm{~kW}$ ). It shows that the pipe-encapsulated wall system can effectively realize heat insulation for the building. In the night-time, the heat removal by the water through the nocturnal sky radiant cooler can reach up to $0.2-0.5 \mathrm{~kW}$. It is slightly larger than the heat flow of internal surface during the daytime. For the accumulated heat transfer during a day (taking the time of $32 \mathrm{~h}-56 \mathrm{~h}$ for example), the accumulated heat transfer of internal surface is $10073.8 \mathrm{~kJ}$. It accounts for $39.4 \%$ of the accumulated heat transfer of the external surface $(25560$ $\mathrm{kJ})$ of the wall, which shows that about $60 \%$ accumulated heat transfer from the outdoor environment is conserved by this pipe-encapsulated PCM wall system. The accumulated heat removal of water through the sky nocturnal radiant cooler is $13218.7 \mathrm{~kJ}$, which accounts for about $51.7 \%$ of the accumulated heat transfer of the external surface. It shows that the performances for the heat insulation and removal of this pipe-encapsulated PCM system is considerable.

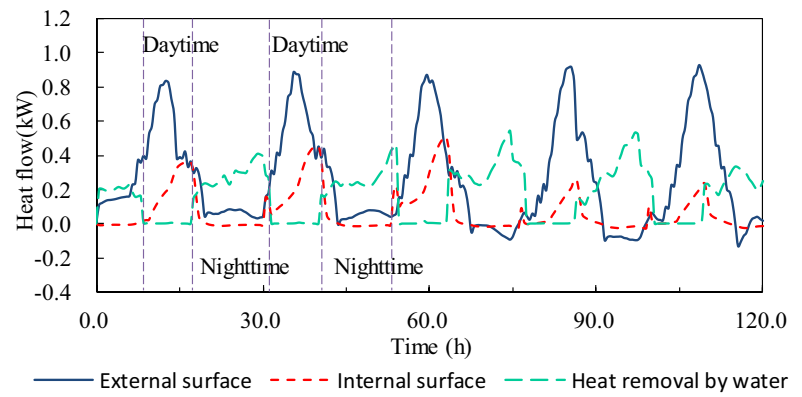

Fig.9. Heat flow of the pipe-encapsulated PCM wall system

The wall surface temperature, water temperature and the liquid fraction of the PCM (i.e., S_PCM) are presented in Fig.10. Due to the phase change latent heat of the PCM, there are inflection points in profiles of the water temperature and internal surface temperature when the PCM is undergoing a phase change (i.e., 0 $<$ S_PCM $<1,0$ for solid phase, 1 for liquid phase). Besides, the PCM is almost melted completely in the daytime (i.e., S_PCM=1), and it can be regenerated in the night-time (i.e., S_PCM=0) with the effect of nocturnal sky radiant cooler. It is favourable to the PCM for the next day's insulation.

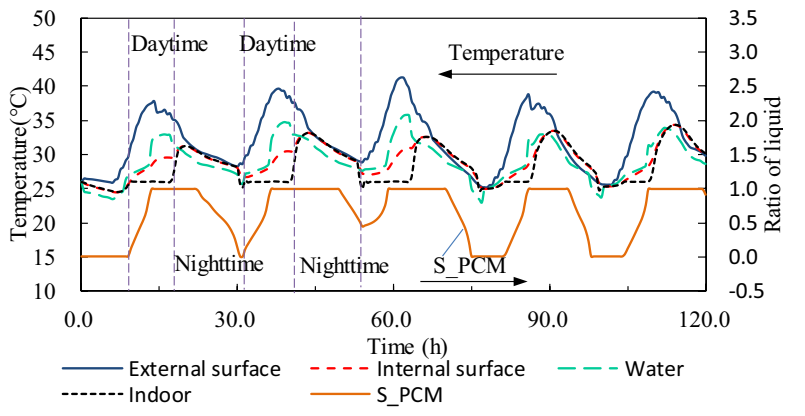


Fig.10. Temperature of the pipe-encapsulated PCM wall system and the liquid fraction of PCM

\section{Conclusions}

This paper proposed a pipe-encapsulated PCM wall system for building insulation and active heat removal. This wall system is composed of the pipe-encapsulated PCM, common wall, nocturnal sky radiant cooler and working fluid circulation system. It is integrated with phase change technology and nocturnal sky radiation technology to realize the building heat insulation and active heat removal with natural cold source.

The common hollow wall model(5R2C), PCM model (4R2C), simplified pipe model(2R1C) and nocturnal sky radiation model are developed to establish system simulation platform for predictions of the thermal performance of this wall system. The parameters of 5R2C wall model and 4R2C PCM model are identified by the frequency-domain finite element wall model and time-domain CFD wall model. The simplified model is validated by comparing the temperature and heat flux predicted by the simplified model and CFD model. The average error of internal surface temperature and water temperature are respectively $0.14{ }^{\circ} \mathrm{C}$ and $0.16^{\circ} \mathrm{C}$. The average error of internal surface heat flux is $1.5 \mathrm{~W}$, and the accumulated heat flow error for 24 hours (one period) is about $1 \%$. Besides, the computational efficiency of the simplified model is significantly higher than the CFD model. It shows that the simplified model for this pipeencapsulated PCM wall system are accurate and reliable.

The thermal performance of a light weight room with pipe-encapsulated PCM wall system in Wuhan is simulated and analysed in this paper. In the daytime (office hours), about 50\%-60\% of heat from the outdoor environment is conserved by this pipe-encapsulated PCM wall system. The accumulated heat removal of water by the nocturnal radiant cooler at night accounts for about $50 \%$ of the accumulated heat transfer from outdoor, and the regeneration efficiency of the PCM are also very high. It shows the pipe-encapsulated PCM wall system has good thermal and energy performance for light weight building. The effect of heat insulation and removal is considerable.

Acknowledgement: This work presented in this paper is financially supported by a grant (No. 51678263) of National Science Foundation of China.

\section{References}

1. M. Delgado, A. Lazaro, J. Mazo, B. Zalba, Renew. Sust. Energ. Rev., 16, 253-273 (2012).

2. X. Kong, C. Yao, P. Jie, Y. Liu, C. Qi, X. Rong, Energ. Buildings., 152, 547-557 (2017)

3. H. Elarga, S. Fantucci, V. Serra, R. Zecchin, E. Benini, Energ. Buildings. 150, 546-557(2017)

4. H. B. Kim, M. Mae, Y. Choi, T. Kiyota, Energ. Buildings. 152, 524-533 (2017).
5. B. M. Diaconu, M. Cruceru, Energ. Buildings., 42, 1759-1772(2010).

6. R.C. Bourne, M.A. Hoeschele, Proceedings ACEEE., 3, 333-345(2000).

7. Y. Man, H. Yang, Y. Qu, Z. Fang, Procedia Engineering. 121, 300-308 (2015).

8. C. Chen, H. GUO, Y. Liu, H. Yue, C. Wang,. Energ. Buildings., 40(5), 882-890 (2008).

9. P. Lamberg, R. Lehtiniemt, A. M. Henell, Int. J. Therm. Sci. 43(3), 277-287(2004)

10. S. Wang, X. Xu, Energ. Convers. Manage., 47, 1927-1941 (2006)

11. X. Xu, S. Wang, Energ. Buildings., 39, 525-536 (2007).

12. Q. Zhu, X. Xu, J. Wang, F. Xiao, Int. J. Therm. Sci. 76, 258-272 (2014)

13. A. Li, Y. Sun, X. Xu, Energ. Buildings., 150, 353375 (2017).

14. E. Kreyszig, Advanced Engineering Mathematics, tenth ed., (John Wiley \& Sons, Hoboken, 2011).

15. Z. Liu, H. Tan, G. Ma, Int. J. Vent., 16(3), 255-267 (2017)

16. S. Ito, N. Miura, J. Energ. Eng., 111(3), 251-256. (1989).

17. E. Erell, Y. Etzion, Bulid. Environ., 35(4), 297-305. (2000)

18. P. Berdahl, M. Martin, Sol. Energy., 32(5), 663-664. (1984)

19. J. Gao, T. Yan, T. Xu, Z. Ling, G. Wei, X. Xu. Appl. Therm. Eng.,146, 364-375 (2019).

20. ASHRAE, Handbook of Fundamentals, Chapter 15 (USA, 2005) 